\title{
How Does a Group of Iranian Youth Conceptualize Their Risky Sexual Experiences?
}

\author{
Mahnaz Noroozi ${ }^{1}$; Effat-al-Sadat Merghati Khoei ${ }^{2,}$; Fariba Taleghani ${ }^{3}$; Mahgol Tavakoli ${ }^{4}$; \\ Ali Gholami ${ }^{5}$ \\ ${ }_{1}^{1}$ Department of Midwifery and Reproductive Health, School of Nursing and Midwifery, Isfahan University of Medical Sciences, Isfahan, IR Iran \\ ${ }^{2}$ Iranian National Centre of Addiction Studies, Institution of Risk Behaviors Reduction, Tehran University of Medical Sciences, Tehran, IR Iran \\ ${ }^{3}$ Department of Adult Health Nursing, School of Nursing and Midwifery, Isfahan University of Medical Sciences, Isfahan, IR Iran \\ ${ }_{5}^{4}$ Department of Psychology, School of Education and Psychology, Isfahan University, Isfahan, IR Iran \\ 5 Department of Psychology, School of Education and Psychology, Isfahan University, Isfa \\ ${ }^{*}$ Corresponding Author: Effat-al-Sadat Merghati Khoei, Iranian National Centre of Addiction Studies, Institution of Risk Behaviors Reduction, Tehran University of Medical Sciences, \\ Tehran, IR Iran. Tel:+98-9125599856, Fax: +98-2188779487, E-mail: effat_mer@yahoo.com
}

Received: February 18, 2014; Revised:April 2, 2014; Accepted: April 27, 2014

\begin{abstract}
Background:There are restrictions as well as lawful and religious prohibition for sexual relationships in Iranian society.
Objectives: This study explores the varied experiential reality of Iranian youth and their risky sexual experiences.

Patients and Methods: Data collection is based on semi-structured interviews with 30 single young men and women. Observation of interactions of youth in different settings has been another source of information. Interviews were microscopically content analyzed. Results: The accounts of risky sexual experiences included gendered behavioral, cultural, and cognitive factors. In the re-contextualizing process, these accounts were categorized by two main themes: "gendered sexual script" and "cultural scenarios of interpersonal interactions". The notion of "male power" was evident in the responses provided by the participants. Women seldom asked for condom use due to limited knowledge about STIs-HIV|AIDS and unpleasant experiences with condoms. Men had limited knowledge about various sexual modes of HIV and STIs transmission and did not use condoms consistently because they had not seen themselves at risk of STIs or HIV as well as their belief about the decrease of sexual pleasure.

Conclusions: Rising youth awareness, creating a positive attitude, and appropriate knowledge about safe sex practices are seminal. It is also vital to ensure access to gender specific sexual and reproductive health services for youths, empower women, and strengthen their sexual assertiveness as well as the elimination of all forms of gender-based inequalities.
\end{abstract}

Keywords:Risk Taking; Behavior; Sexual Behavior; Youth

\section{Background}

The sexual behaviors of adolescents and youth are considered a main health priority because of the high prevalence of human immunodeficiency virus/acquired immunodeficiency syndrome (HIV/AIDS) and sexually transmitted infections (STIs) $(1,2)$. Reports indicate that about $50 \%$ out of 35.3 million people are infected with HIV and have had this infection from before they were 25 years of age (3). Each day, some 500,000 young people, mostly young women, are infected with an STI (excluding HIV) (4). Notably, the number of many STIs such as chlamydia and gonorrhoea is higher among adolescents and youth than in adults (5). Globally, girls and boys reach puberty at younger ages and they postpone marriage $(6,7)$. They are at risk of engaging in premarital sexual encounters and confronting with HIV/AIDS, STIs, and unwanted early pregnancies due to the long gap between marriage and puberty (8). In Asia, national surveys have revealed that premarital sex is less when compared with developed countries. However, smaller in-depth studies that focus on youth have indicated that sexual activity has clearly increased (9). Risky sexual behaviors are widely discussed in academia. Experts in the field of sexual health have focused on the social pressure on youths to initiate early sexual behaviors and follow beauty models from the media (10). Various issues such as social pressures along with the increase of free time, being away from family monitoring and control, as well as peer influences; all lead youngsters to early sexual experiences $(11,12)$. In Iran, out of the 75 million population, young people make a significant proportion of the population. The results of the most recent census (2011) indicated that about $20 \%$ of the population (about 15 million people) are in the age 15-24 age group (13). Risky sexual behaviors have increased among Iranian young people (14). In recent years, HIV has increased through sexual transmission. The statistics indicate that by September 2011, a total of 23,497 people were identified with HIV/AIDS in Iran (15). Like other countries, youth in Iran are also exposed

Copyright (C) 2015, Iranian Red Crescent Medical Journal. This is an open-access article distributed under the terms of the Creative Commons Attribution-NonCommercial 4.0 International License (http://creativecommons.org/licenses/by-nc/4.0/) which permits copy and redistribute the material just in noncommercial usages, provided the original work is properly cited. 
to premarital sexual experiences and more likely to engage in risky sexual behaviors. The findings of previous studies have shown that a large number of Iranian youth are not well informed about safe sexual behaviors and lack the skills to negotiate safe sex. Therefore, they might be engaged in unprotected and risky sexual behaviors, unwanted pregnancies, and unsafe abortions (14). There are restrictions, lawful and religious prohibition, and regulation for sexual activities/relations in Iranian society. Despite these restrictions, it seems that there is a new culture of sexuality that guides the youth in their sexual interactions. We must understand the process of formation and determinants of the sexual behaviors among young people to prevent risky sexual behaviors.

\section{Objectives}

In this study, we explore the varied experiential reality of Iranian youth risky sexual experiences.

\section{Patients and Methods}

In this qualitative inquiry, mini-ethnography was employed to collect data from January 2012 until February 2013. In response to "how do Iranian young people conceptualize their risky sexual behaviors?", we used miniethnography to explore the culture of sexuality and the patterns of risky sexual behaviour among the youth. Participants were 30 single men $(n=13)$ and women $(n=17)$, 18-24 years of age (Table 1) living in Isfahan, the second biggest city in Iran. In Isfahan, people are mainly conservative in sexuality related subject matters.

We purposely approached the participants who had sexual activities and volunteered to participate in the study by telephone. Potential participants were recruited from the university campus, parks, and gyms. Our recruitment continued by using a network sampling technique. Women and men were selected on equal distributions. Moreover, the researchers used different parks and gyms around the city to be able to choose people of different economic and social status (maximum variation sampling). Approval for the study was obtained from the Research Ethics Committee of Isfahan University of Medical Sciences (ethical approval code: 390436). Ethical considerations by getting informed consent as part of the research process, stating the purpose of the study, the method of data collection, as well as record, anonymity, information, and confidentiality and removing the recorded files after use. The right of research withdrawal at any time and presenting the results if asked and getting introduction letters and passing legal processes were done. Writing down initial preconceptions, values, and beliefs about the target group based on the investigators previous working experiences with youth led the research team to produce the interview guide. Face-to-face in-depth semi-structured interviews were used to collect data. Most of the interviews were conducted in one session. Sessions with participants who provided thorough

\begin{tabular}{|c|c|c|c|c|}
\hline Pseudonym & Gender & Age, $y$ & Educational & Job Status \\
\hline Qiomars & Male & 23 & $\begin{array}{l}\text { University } \\
\text { student }\end{array}$ & self employed \\
\hline Banafshe & Female & 20 & $\begin{array}{l}\text { University } \\
\text { student }\end{array}$ & self employed \\
\hline Rose & Female & 19 & $\begin{array}{l}\text { University } \\
\text { student }\end{array}$ & \\
\hline Mina & Female & 18 & $\begin{array}{l}\text { University } \\
\text { student }\end{array}$ & \\
\hline Keivan & Male & 22 & Diploma & self employed \\
\hline Soosan & Female & 20 & $\begin{array}{l}\text { University } \\
\text { student }\end{array}$ & \\
\hline Shahab & Male & 21 & Diploma & self employed \\
\hline Shahin & Male & 22 & $\begin{array}{l}\text { University } \\
\text { student }\end{array}$ & \\
\hline Sahand & Male & 24 & Diploma & self employed \\
\hline Kokab & Female & 22 & $\begin{array}{l}\text { University } \\
\text { student }\end{array}$ & \\
\hline Bizhan & Male & 19 & Diploma & self employed \\
\hline Zhila & Female & 23 & $\begin{array}{l}\text { University } \\
\text { student }\end{array}$ & \\
\hline Niloufar & Female & 21 & $\begin{array}{l}\text { University } \\
\text { student }\end{array}$ & \\
\hline Shaghayegh & Female & 21 & $\begin{array}{l}\text { University } \\
\text { student }\end{array}$ & \\
\hline Kambiz & Male & 19 & Diploma & self employed \\
\hline Azalia & Female & 20 & $\begin{array}{l}\text { University } \\
\text { student }\end{array}$ & \\
\hline Nastaran & Female & 21 & $\begin{array}{l}\text { University } \\
\text { student }\end{array}$ & \\
\hline Kavoos & Male & 24 & Bachelor & self employed \\
\hline Manoochehr & Male & 23 & $\begin{array}{l}\text { University } \\
\text { student }\end{array}$ & self employed \\
\hline Narges & Female & 21 & $\begin{array}{l}\text { University } \\
\text { student }\end{array}$ & \\
\hline Orkideh & Female & 22 & $\begin{array}{l}\text { University } \\
\text { student }\end{array}$ & \\
\hline Behzad & Male & 23 & $\begin{array}{l}\text { University } \\
\text { student }\end{array}$ & self employed \\
\hline Gelayol & Female & 24 & Bachelor & jobless \\
\hline Laleh & Female & 18 & $\begin{array}{l}\text { University } \\
\text { student }\end{array}$ & \\
\hline Parastoo & Female & 18 & $\begin{array}{l}\text { University } \\
\text { student }\end{array}$ & \\
\hline Bahram & Male & 19 & $\begin{array}{l}\text { University } \\
\text { student }\end{array}$ & \\
\hline Bahman & Male & 20 & $\begin{array}{l}\text { University } \\
\text { student }\end{array}$ & \\
\hline Parvane & Female & 24 & Bachelor & \\
\hline Baran & Female & 23 & Bachelor & jobless \\
\hline Kave & Male & 21 & $\begin{array}{l}\text { University } \\
\text { student }\end{array}$ & \\
\hline
\end{tabular}


information about the topic were divided in two or three sessions to avoid a long and boring interview. The duration of the interviews varied from 45-135 min. The interviewer's field of expertise was reproductive health and as a well-known and accessible person could make the trust building process shorter. Interviews were started by the main question of "what do you think about friendship and relationship between single woman and man before getting married?" Later, participant responses guided the interview process. By continuation of the interview, more specific questions about the beginning of sexual relations, sexual activities, and the youth perceptions and beliefs about risky sex, HIV/AIDS and STIs, protective behaviors, and other topics of this field were questioned. All interviews were done in an agreed place such as a park. We found four key informants (one man and three women) after interviewing 12 individuals and selected them based on their sexual experiences. They knew many young men and women who had already initiated sexual activities. These four key informants connect the investigators to the youth network. They showed their capability of being familiar with the culture of sexuality in terms of language of use, slang terms, and so on. They had chances to observe sexual interactions among their peers and circumstances that were impossible to be observed by the researchers. The key informants also provide indigenous testimonials as the information source of their surrounding values. In this way, they can play a key role in unveiling the complex mysteries of their sexual behaviors. In this study, the investigators also observed them in different fields as well as with the interview process. They also used key informants to observe acts, behaviors, talks, communications, and sexual interactions in different natural environments such as internet cafes, coffee shops, restaurants, shopping centers, parks, cinemas, buses, gyms, university, and recreational complexes. The key informants were asked to write whatever seems to have a sexual nature among youth. They were asked to write these topics with a detailed look irrespective of any interpretation. The key informants were trained to write field notes and a reflexive journal on a daily base. They reported 35 episodes of field observation. All interviews were transcribed word by word by the investigators. The scripts, field notes, and the recoded observations were analyzed employing conventional content analysis. Data credibility was reassured with long lasting involvement with the participants and data collection. We created a rapport by a friendly relationship with the participants and constant relationships with the key informants that led us to have a trustful data collection procedure. In order to truly and deeply understand participant accounts, the researchers reread the data at least 3 times in different situations. Given that the investigators were from a different generation compared to that of participants, they stayed in touch with key informants and discussed the various subject matters. The investigators also sought to reach the contrastive evidence by meeting and inter- viewing them at different layers of society. Discussion sessions with three participants were provided to collect their final views about the topic to fulfill member checking. External checking was conducted with three academics including an expert in the field of sexual behaviour, nursing, and clinical psychology. They first rechecked the coded scripts, and mentioned their opinions about the coding method, later they suggested their own code lists. Data transferability was made possible by reviewing the findings by 4 young people (including 2 young males and 2 females) who had the similar characteristics compared to that of the participants of the study but they did not take part in the study. They found the findings similar to the behavioral patterns they used to observe throughout real life. To address the dependability of data, an expert researcher who was not related to the study analyzed two of scripts.

\section{Results}

The youth accounts of risky sexual experiences included gendered behavioral, cultural, and cognitive elements. In the re-contextualizing process, these accounts were categorized into two main themes: a. gendered sexual script and b. cultural scenarios of interpersonal interactions. Women indicated that in their sexual activities they have always played the role of a male follower. They were used to accepting the man's decision through sexual encounters. This concept is also seen in families and in larger society. From a woman's perspectives, men tend to see a woman as a tool for seeking sexual gratification. The majority of women believed that the above perception lead men to look for a variety of sexual partners only to perform a functional sexual act. Internalizing this belief reinforced women to accept any sexual performance offered by men. It seems keeping the partner is the main intention of women to hold back their own sexual interests or preferences. Niloufar, a 21 year-old female believed that women have to follow the decisions their partners make through a sexual encounter:

“... He will say, okay! Let's cut this relation! I can get sexual satisfaction from others too, and we can just be friends..., it's their trick! Kind of pressure. Then you will be afraid of losing him, and may accept anything" (Interview 6).

Different societal expectations for sexual behavior were related to femininity and masculinity and were highlighted by the majority of participants. The participants mentioned that when a girl loses her virginity, it taints her social dignity and her marital life in the future, so to stay virgin until marriage is of paramount importance. In contrast, virginity is not applied to men. They have freedom to be involved in premarital sexual relationships and this would not be regarded as any threat to their future. The women pointed out more depth of ideas on virginity, femininity, and sexuality than simply describing it. Orkideh, a 22 year-old female described virginity as the 
hallmark for being proud of a girl in the society. From her point of view, a girl's choice of marriage is highly dependent on her virginity; and in the case of losing it, she will be regarded as devastated and fallen:

"... In our society the norm is that the girl who has vaginal sexual relationship is regarded as a perverted useless girl. Girl's virginity is very important for many boys..., those who would marry with a perverted girl are few" (Interview 4).

One of the important points about the female participants of the study was the paramount importance of virginity as a cultural value. Most of them considered sexual intercourse a risky sexual behaviour because it damages hymen or could lead to pregnancy. Banafshe, 20 defined a damaged hymen or pregnancy as the types of risky behaviour, which is dangerous especially for females. She does not refer to HIV/AIDS and STI vulnerability:

"....When a girl is at risk, it means she has done dangerous things. By dangerous I mean damaged Hymen, or unwanted pregnancy" (Interview 15).

Analysis of the data showed that virginity as a cultural norm causes common sexual acts among the participants. They usually avoided premarital vaginal sex throughout their romantic relationships. Therefore, women commit to different forms of sexual practices (i.e. anal, oral, and mammary sex, among others). The majority of women believed that these sexual practices are not risky because these forms of behaviour would not damage the hymen.

The majority of participants pointed out the fear of arranged marriage as the main reason for men to refuse vaginal intercourse with a virgin girl. Kambiz, a 19 yearold male has considered forceful marriage as risky experience:

"...If you want to have a vaginal sex, then you are forced to marry with the girl, this can be the first possible outcome in the case of such problems" (Interview 3).

Most female participants believed that the spread of AIDS is not remarkable in Iran and their chance of getting infection by having sexual contact is little. They named vaginal sex, addiction (by injection), and blood products as the only way to be infected with HIV. They believed that AIDS could not be their disease and it is not regarded as an individual threat. They knew a little about STIs and mentioned that the transmitting method of gonorrhoea, syphilis, and hepatitis B is vaginal sex. They said that transmitting chance of such diseases is even fewer than for AIDS. In addition, the female participants who had limited condom usage as a contraceptive method did not know about its usefulness for HIV/AIDS and STIs protection. The participants stated that mostly females are not interested in condom usage in oral sex. This is because condoms taste like rubber or an indication of decreased sexual pleasure for males; and females are also not interested in the rubber taste ...it's disgusting to taste it. It rarely happens that a female want to from vaginal sex. Some of them referred to oral sex as a way of being infected to HIV, and they believed the probability of being infected from oral sex is little. Most male participants knew a little about STIs, and they only knew about Syphilis and Gonorrhoea transmission by vaginal sex. They believed the probability of being infected to Syphilis and Gonorrhoea is a little from sexual relation, and is even fewer than AIDS. All of the male participants knew about condom method of protection in vaginal sexual relations. Participants said that most males do not use condom in anal sex either with their steady or casual partners. In addition, they do jxuhcucgs7sccgcxz 24 yearold male has stated that the reason that male partners do not use protection in oral-vaginal sex is because of their lack of information and familiarity:

"... Well, AIDS is a type of diseases which enters human body by mucus, and mouth has mucus! Maybe, many people don't know this, and may think that vaginal sex can get them infected to AIDS. The problem is that many people don't know" (Interview 13).

The findings showed that males act different in their sexual relations in comparison to females. Males use condoms in their sexual relations with prostitutes and single non-virgin females commit to vaginal sex, because they think that their probability of getting infected with AIDS with such partners is greater. The point is that males are looking for sexual pleasure in relationships and they think the probability of being infected with AIDS is low, so they do not consistently use condoms.

\section{Discussion}

The findings showed that gender plays a substantial role in the formation of participant autonomy for sexual encounters. Being man or woman is the main criterion for how sexual behaviors are defined. Also, in western cultures, the sexual scripts for sexual activity are clearly different for men and women (16). Potential reason that the sexual script differs by gender in our study is the meaning of power attached to sexual relationships, i.e. the power of manhood. Masculine gender role had affected female participants. They hold the belief and the power of making decision throughout the friendship would be up to the man. They believed that women have to follow the decisions their partners make through sexual encounters and pointed out the inability of women in rejecting unwanted sex. Langen mentions that gender power imbalance translates into a power imbalance in the sexual interactions that increase vulnerability to HIV (17). Reports emphasized that gender inequalities have an undeniable effect on a youth's life and women in particular (18). The accounts of our participants support new gender norms that have been generated among them than for the changing gender roles concerning sexual behaviors in Iranian culture. According to the collected data, female virginity was defined within a complex web of morality. Girls and boys considered virginity as the core determinant of a girl's sexuality. This perspective 
makes men feel free to have premarital sexual relationships and seek to satisfy their sexual needs without any concern through their current or future romantic encounters. Kelly et al. showed that virginity among Roma (Gypsies) females and males is a strong cultural norm and must be taken care of until marriage (19). Although the majority of participants expressed that they did not connect strongly with cultural scenarios of their sexual scripts, they had maintained strong connections to the concept of virginity as a cultural and valued norm. The results showed that in premarital friendships, a large number of women involved in non-vaginal sex due to the partner's demand. These forms of sexual encounters were done to keep dating long lasting, a promise of intact virginity and to not damage their future in terms of marriage. As strategies to maintain virginity, non-vaginal sexual contacts among young people have been shown by Lindberg et al. (20). Data analysis showed that limited knowledge and misconceptions about HIV/AIDS, STIs, and the participant sexual beliefs had a negative effect on their protective sexual behaviors, i.e. condom usage. Female participants have little knowledge about HIV/AIDS and STIs transmission. In this regard, they do not think they are in danger of being infected to these diseases (especially STIs). The findings show that a female's lack of awareness about condom usage in having a safer sexual relationships and that condoms have a disgusting taste during oral sex has made them not to request their usage either from steady or casual partners in non vaginal sexual acts. With these points, such sexual encounters (unprotected) increase the vulnerability to HIV/AIDS and STIs. Another study has also shown that not using condoms in anal sex is the riskiest action with regards to being infected by HIV (21). Based on the results of the study, although male participants were aware of HIV risk at a cognitive level, they had limited knowledge about various sexual modes of HIV and STIs transmission. In addition, another reason that male participants do not use condoms (or do not consistently use them) is their belief in a decrease of sexual pleasure and the mentality of being safe from acquiring STIs/HIV. Abdulraheem and Fawole stated that the main reason that adolescents and youth of Nigeria do not use condoms is that their sexual pleasure decreased (22). Accordingly, the importance of providing a culturally sensitive, comprehensive, and systematic training in the society about HIV/AIDS and STIs is evident. The teachings must be aimed at educating the youth and females in particular about HIV and its transmission to each individual. By educating the youth about dangers of premarital sexual relations and focusing on the fact that some types of STIs such as genital warts will be transmitted even by using condoms (23). The importance and necessity of premarital abstinence can be justified for them. It is vital to ensure men and women access to sexual and reproductive health services, improve the social supports that empower women and strengthen their confidence as well as the elimination of all forms of gender inequality. In addition, by taking steps toward creating positive attitudes about condom usage and its role in individual protection can make its usage more constant and correct. The findings of this research like other qualitative researches have little generalization. Although by using various strategies to increase the acceptance and objectivity, it seems the findings have enough validity and reliability.

\section{Authors' Contributions}

Study concept and design: Mahnaz Noroozi, Effat-alSadat Merghati Khoei, Fariba Taleghani, Mahgol Tavakoli and Ali Gholami; Acquisition of data: Mahnaz Noroozi; Analysis and interpretation of data: Mahnaz Noroozi, Effat-al-Sadat Merghati Khoei and Fariba Taleghani; Drafting of the manuscript: Mahnaz Noroozi, Effat-al-Sadat Merghati Khoei and Fariba Taleghani; Critical revision of the manuscript for important intellectual content: Effat-al-Sadat Merghati Khoei; Statistical analysis: Mahnaz Noroozi, Effat-al-Sadat Merghati Khoei and Fariba Taleghani; Administrative, technical, and material support: Effat-al-Sadat Merghati Khoei; Study supervision: Effat-al-Sadat Merghati Khoei, Fariba Taleghani and Ali Gholami.

\section{Funding/Support}

By Isfahan University of Medical sciences, Research proposal No: 390436 .

\section{References}

1. Goesling B, Colman S, Trenholm C, Terzian M, Moore K. Programs to reduce teen pregnancy, sexually transmitted infections, and associated sexual risk behaviors: a systematic review. J Adolesc Health. 2014;54(5):499-507.

2. Anwar M, Sulaiman SA, Ahmadi K, Khan TM. Awareness of school students on sexually transmitted infections (STIs) and their sexual behavior: a cross-sectional study conducted in Pulau Pinang, Malaysia. BMC Public Health. 2010;10:47.

3. Sidibé M. UNAIDS report on the global AIDS epidemic.UNAIDS Geneva: Joint United Nations Programme on HIV/AIDS; 2010.

4. United Nations Population Fund.. Breaking the cycle of sexually transmitted infections.: UNFPA; 2013.

5. Conejero C, Cannoni G, Merino PM, Bollmann J, Hidalgo C, Castro M, et al. [Screening of Neisseria gonorrhoeae and Chlamydia trachomatis using techniques of self collected vaginal sample in young women]. Rev Chilena Infectol. 2013;30(5):489-93.

6. UNFPA.. Adolescent sexual and reproductive health: Toolkit for humanitarian settings.: United Nations Population Fund; 2009.

7. Finer LB. Trends in premarital sex in the United States, 1954-2003. Public Health Rep. 2007;122(1):73-8.

8. Ompad DC, Strathdee SA, Celentano DD, Latkin C, Poduska JM, Kellam SG, et al. Predictors of early initiation of vaginal and oral sex among urban young adults in Baltimore, Maryland. Arch Sex Behav. 2006;35(1):53-65.

9. Tangmunkongvorakul A, Carmichael G, Banwell C, Utomo ID, Sleigh A. Sexual perceptions and practices of young people in Northern Thailand. J Youth Stud. 2011;14(3):315-39.

10. Nobelius AM, Kalina B, Pool R, Whitworth J, Chesters J, Power R. Delaying sexual debut amongst out-of-school youth in rural southwest Uganda. Cult Health Sex. 2010;12(6):663-76.

11. Cornell JL, Halpern-Felsher BL. Adolescents tell us why teens have oral sex. JAdolesc Health. 2006;38(3):299-301. 
12. Assefa S, Dessalegn W. Premarital sexual practice among school adolescents in Nekemte Town, East Wollega. Ethiop J Health Dev 2008;22(2):167-73.

13. Statistical Centre of Iran.. National population and housing census. 1ed edTehran: Statistical centre of Iran; 2012.

14. Mohammadi MR, Mohammad K, Farahani FK, Alikhani S, Zare M, Tehrani FR, et al. Reproductive knowledge, attitudes and behavior among adolescent males in Tehran, Iran. Int Fam Plan Perspect. 2006;32(1):35-44

15. National AIDS committee secretariat.. Islamic Republic of Iran AIDS progress report.; 2012.

16. Wiederman MW. The Gendered Nature of Sexual Scripts. Fam J. 2005;13(4):496-502.

17. Langen TT. Gender power imbalance on women's capacity to negotiate self-protection against HIV/AIDS in Botswana and South Africa. Afr Health Sci. 2005;5(3):188-97.
18. Tangmunkongvorakul A, Kane R, Wellings K. Gender double standards in young people attending sexual health services in Northern Thailand. Cult Health Sex. 2005;7(4):361-73.

19. Kelly JA, Amirkhanian YA, Kabakchieva E, Csepe P, Seal DW, Antonova R, et al. Gender roles and HIV sexual risk vulnerability of Roma (Gypsies) men and women in Bulgaria and Hungary: an ethnographic study. AIDS Care. 2004;16(2):231-45.

20. Lindberg LD, Jones R, Santelli JS. Noncoital Sexual Activities Among Adolescents. J Adolesc Health. 2008;43(3):231-8.

21. Dake JA, Price JH, McKinney M, Ward B. Midwestern Rural Adolescents' Anal Intercourse Experience. J Rural Rural Health. 2011;27(2):196-204.

22. Abdulraheem IS, Fawole OI. Young People's Sexual Risk Behaviors in Nigeria. Journal of Adolescent Research. 2009;24(4):505-27.

23. Carter JR, Ding Z, Rose BR. HPV infection and cervical disease: a review. Aust N Z J Obstet Gynaecol. 2011;51(2):103-8. 